\title{
Isolated pink papule on the chest
}

\author{
Zachary Wolner ${ }^{1}$, Melissa P. Pulitzer ${ }^{2}$, Michael A. Marchetti ${ }^{1}$
}

1 Dermatology Service, Memorial Sloan Kettering Cancer Center, New York, NY, USA

2 Dermatopathology Service, Memorial Sloan Kettering Cancer Center, New York, NY, USA

Citation: Wolner Z, Pulitzer MP, Marchetti MA. Isolated pink papule on the chest. Dermatol Pract Concept. 2017;7(1):3. DOI: https://doi. org/10.5826/dpc.0701a03

Copyright: @2017 Wolner et al. This is an open-access article distributed under the terms of the Creative Commons Attribution License, which permits unrestricted use, distribution, and reproduction in any medium, provided the original author and source are credited.

Corresponding author: Michael A. Marchetti, MD, 16 East 60 ${ }^{\text {th }}$ Street, New York, NY 10022, USA. Tel. 646-888-6016. Email: marchetm@ mskcc.org

\section{Report of Cases}

Case 1: A man in his fifties with a history of Hodgkin lymphoma treated 20 years prior with the Stanford $\mathrm{V}$ protocol and mantle field radiation (total dose: 36 Gray) presented for skin examination. A $3 \mathrm{~mm}$ pedunculated pink papule was found on the right chest within the prior radiation field (Figure 1A). The lesion was asymptomatic and of unknown duration. There was no history of change, bleeding, or itching. Polarized dermoscopy of the papule revealed irregular linear and looped branching vessels that terminated in a semicircular or circular fashion, also termed "cherry-blossom" vessels (Figure 2A).

Histopathologic examination revealed a pedunculated well-circumscribed nodular epithelial tumor composed of uniform cuboidal cells with round basophilic monomorphic nuclei. Multiple broad cords of the anatomizing tumor epithelium connected to the overlying epidermis, surrounding characteristic sclerotic well-vascularized stroma (Figure 3A).

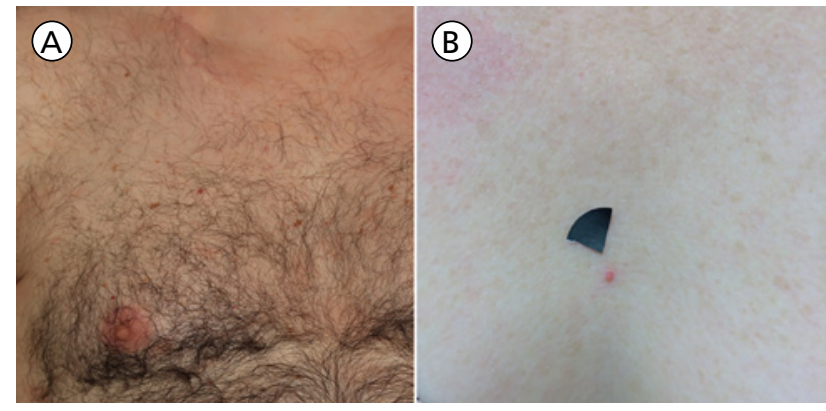

Figure 1. Non-pigmented eccrine poroma. A) Clinical image showing a pink papule on the right upper chest. B) Clinical image showing a pink papule on the presternal chest. [Copyright: @2017 Wolner et al.]
Case 2: A woman in her fifties with a history of basal cell carcinoma and B-cell acute lymphoblastic leukemia status post two allogenic hematopoietic stem cell transplants (total body irradiation induction dose of: $13.75 \mathrm{~Gy}$ ) presented for skin examination. A new, asymptomatic $2 \mathrm{~mm}$ pedunculated pink papule was found on the presternal chest (Figure 1B). Polarized dermoscopy of the lesion revealed semicircular/ circular branching vessels originating from a common stem vessel (Figure 2B).

Histopathological examination revealed a polypoid epithelial tumor comprised of broad downgrowths of cuboidal epithelium clearly demarcated from overlying epidermis amidst a background of hyalized/sclerotic highly vascular stroma. Small ducts with a pink cuticle were noted within epithelial bands (Figure 3B).

What is the diagnosis?

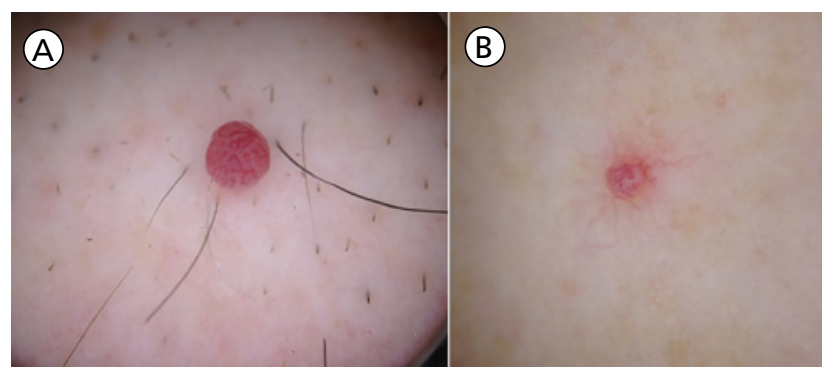

Figure 2. Non-pigmented eccrine poroma. Polarized, non-contact dermoscopy images of a pedunculated pink papule with irregular branching vessels that terminate in circular and semi-circular structures. A is from Case 1 and B is from Case 2. [Copyright: (O2017 Wolner et al.] 


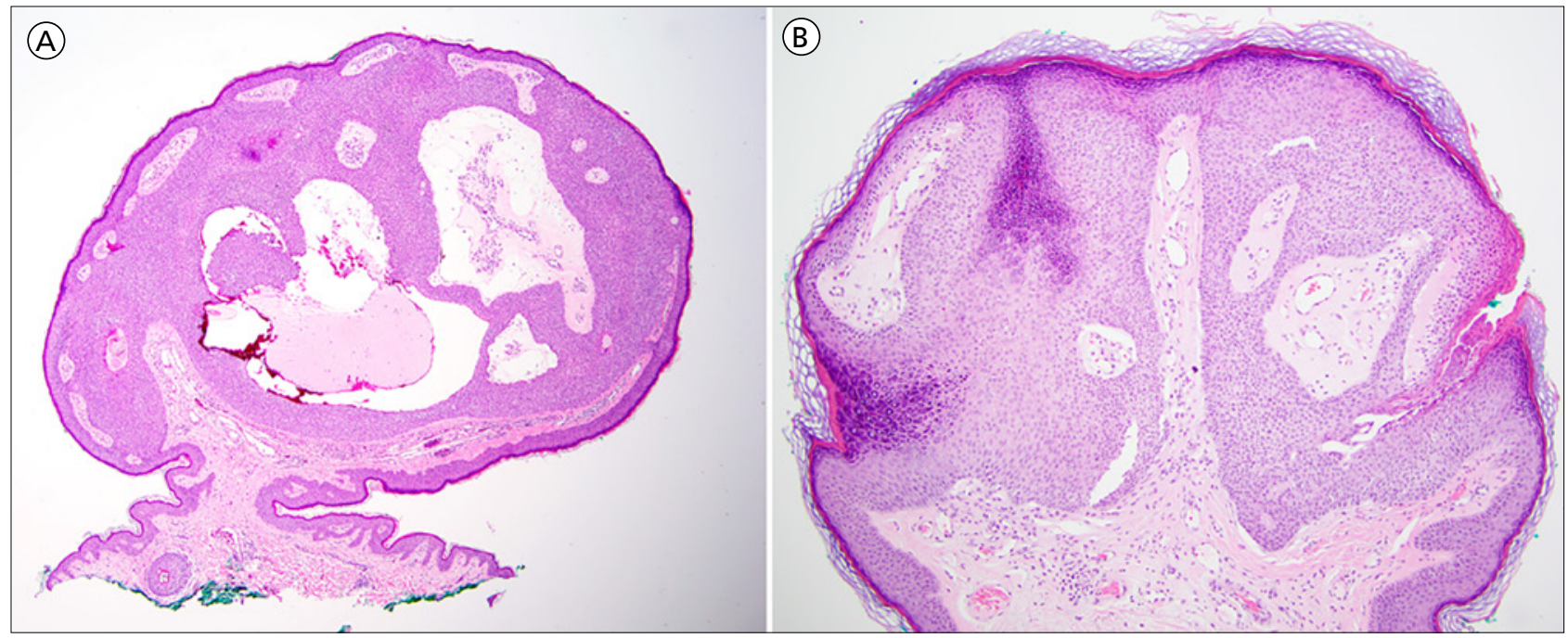

Figure 3. A) Non-pigmented eccrine poroma: photomicrograph showing an exophytic, well-circumscribed nodular epithelial tumor with uniform cuboidal cells, round basophilic monomorphic nuclei, and sclerotic vascularized "poroma stroma" (hematoxylin-eosin stain, original magnification X20). B) Non-pigmented eccrine poroma: photomicrograph showing a pedunculated epithelial proliferation characterized by sharply demarcated broad epithelial downgrowths of cuboidal cells and characteristic sclerotic and vascular stroma (hematoxylin-eosin stain, original magnification X20). [Copyright: @2017 Wolner et al.

\section{Answer}

\section{Eccrine poroma}

\section{Discussion}

Eccrine poromas are benign cutaneous adnexal neoplasms with terminal eccrine duct differentiation. In 2016, Ito et al reviewed 376 lesions and found that eccrine poromas occur most frequently on the lower extremities $(44.4 \%)$, followed by the scalp (16.2\%), trunk (11.7\%), upper extremities (11.4\%), face $(9.8 \%)$, and neck $(3.7 \%)$ [1]. Typically eccrine poromas appear as solitary plaques, papules, or nodules, but multiple tumors can be seen. Poromas commonly contain highly vascularized stroma but can uncommonly have pigmentation [2].

The differential diagnosis of a non-pigmented papule arising in the field of prior radiotherapy should include amelanotic melanoma, squamous cell carcinoma, adnexal neoplasm, and basal cell carcinoma. Interestingly, eccrine poromas have been associated with radiotherapy and hematologic malignancy $[3,4]$.
The dermoscopic features of nonpigmented eccrine poromas are variable (Table 1). A "polymorphous" vascular pattern consisting of hairpin, glomerular, and irregular linear vessels in a single lesion has been frequently described [3,5-15]. The most common features include a structureless pink-white background (48\%), hairpin (loop) vessels (47\%), "frog-egg appearance" (39\%), glomerular vessels (35\%), red lacunae $(27 \%)$, ulcers $(24 \%)$, linear-irregular vessels $(23 \%)$, and leaf-like or cherry-tree vessels $(21 \%)$. The cases described herein showed irregular branching and looped vessels that terminated in semicircular or circular structures, which raised the suspicion for eccrine poroma [7,11]. These vascular structures may correlate with localization of proliferative vessels within the curved "canals" of tumor stroma.

Variation among dermoscopic characteristics reported in the literature can depend on whether contact and/or polarized dermoscopy was used, the location of the lesion, or variation in the angles of the tumor and the dermatoscope [10]. Larger studies are needed to determine the sensitivity and specificity of the dermoscopic criteria for eccrine poroma. 


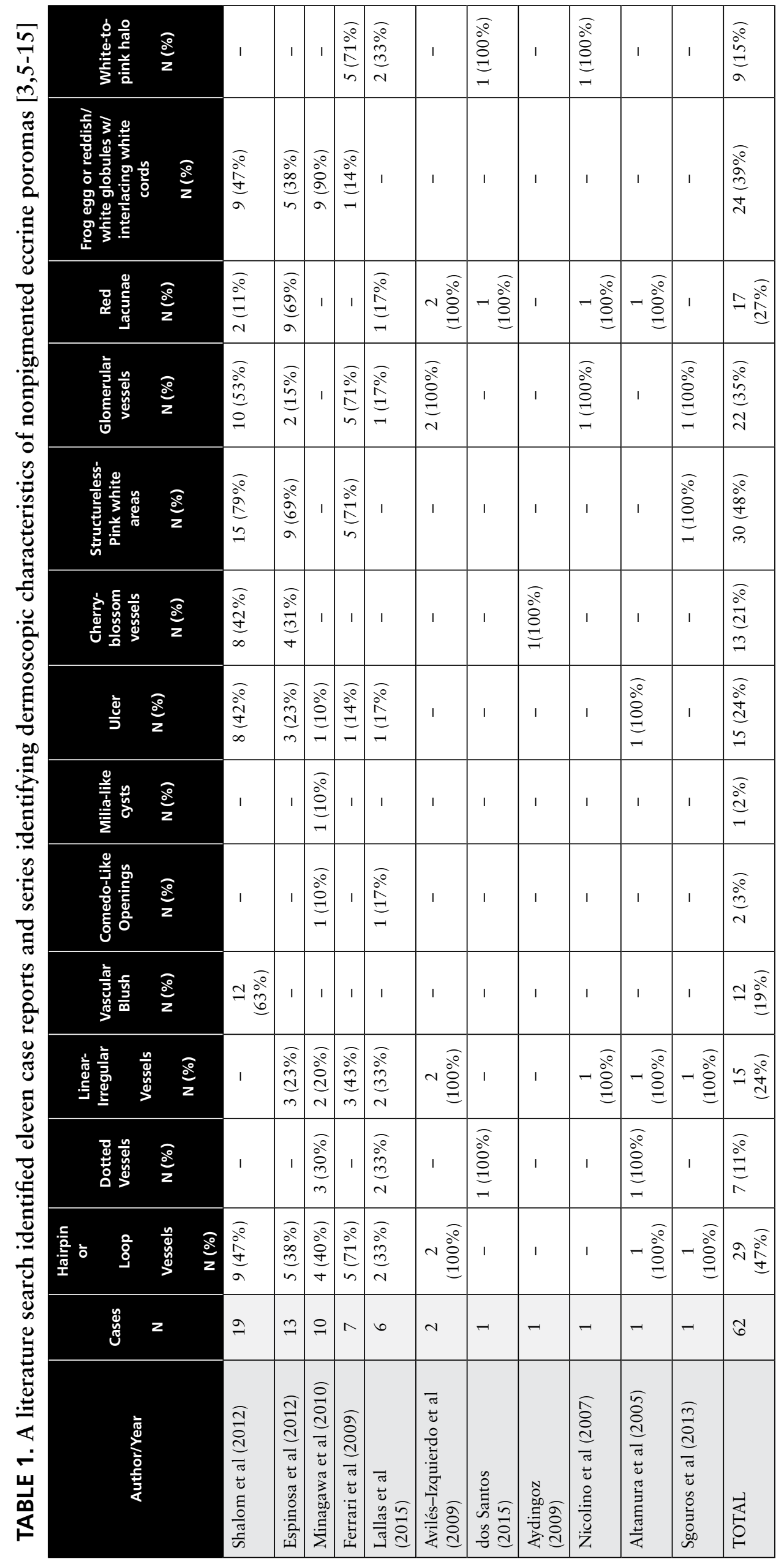




\section{References}

1. Ito K, Ansai SI, Fukumoto T, Anan T, Kimura T. Clinicopathological analysis of 384 cases of poroid neoplasms including 98 cases of apocrine type cases. J Dermatol. May 14 2016. [Epub ahead of print]

2. Bolognia J, Jorizzo JL, Schaffer JV. Dermatology. Philadelphia: Elsevier Saunders; 2012.

3. Miura T, Yamamoto T. Eruptive poromatosis following radiotherapy. Am J Dermatopathol. 2013;35(5):615-617.

4. Mahlberg MJ, McGinnis KS, Draft KS, Fakharzadeh SS. Multiple eccrine poromas in the setting of total body irradiation and immunosuppression. J Am Acad Dermatol. 2006;55(2 Suppl):S46-49.

5. Altamura D, Piccolo D, Lozzi GP, Peris K. Eccrine poroma in an unusual site: a clinical and dermoscopic simulator of amelanotic melanoma. J Am Acad Dermatol. 2005;53(3):539-541.

6. Ferrari A, Buccini P, Silipo V, et al. Eccrine poroma: a clinicaldermoscopic study of seven cases. Acta Derm Venereol. 2009;89 (2):160-164.

7. Aydingoz IE. New dermoscopic vascular patterns in a case of eccrine poroma. J Eur Acad Dermatol Venereol. 2009;23(6):725726.

8. Aviles-Izquierdo JA, Velazquez-Tarjuelo D, Lecona-Echevarria
M, Lazaro-Ochaita P. [Dermoscopic features of eccrine poroma]. Actas Dermosifiliogr. 2009;100(2):133-136.

9. Minagawa A, Koga H, Takahashi M, Sano K, Okuyama R. Dermoscopic features of nonpigmented eccrine poromas in association with their histopathological features. Br J Dermatol. 2010;163 (6):1264-1268.

10. Shalom A, Schein O, Landi C, Marghoob A, Carlos B, Scope A. Dermoscopic findings in biopsy-proven poromas. Dermatol Surg. 2012;38(7 Pt 1):1091-1096.

11. Espinosa AED, Ortega BC, Venegas RQ, Ramírez RG. Dermoscopy of non-pigmented eccrine poromas: study of Mexican cases. Dermatol Pract Concept. 2013;3(1):25-28.

12. Sgouros D, Piana S, Argenziano G, et al. Clinical, dermoscopic and histopathological features of eccrine poroid neoplasms. Dermatology. 2013;227(2):175-179.

13. dos Santos BS. Clinical and dermoscopic features of eccrine poroma. Indian J Dermatol Venereol Leprol 2015;81(3):308-309.

14. Nicolino R, Zalaudek I, Ferrara G, et al. Dermoscopy of eccrine poroma. Dermatology. 2007;215(2):160-163.

15. Lallas A, Chellini PR, Guimaraes MG, et al. Eccrine poroma: the great dermoscopic imitator. J Eur Acad Dermatol Venereol. 2016;30(10):e61-e63. 